\title{
CODIFYing social issues in organizations: scope and perspectives
}

\author{
Tzafrir Shay $\cdot$ Enosh Guy $\cdot$ Parry Emma • \\ Stone Dianna
}

\begin{abstract}
The purpose of the current paper is to present the scope of the Journal of Managerial Psychology. From our perspective, the organization and its members are being affected and are affecting their internal and external contexts. The external environment interacts with the internal one through various mechanisms, including communication, observation, diffusion, interaction, friction, and yearning. Those mechanisms operate simultaneously yet differently at different systemic levels (community, organization, group, and individual). Actors (including institutions, organizations, their members, and stakeholders in the environment) need to develop awareness, strategies, and tactics for approaching those differing levels, the ways by which the various mechanisms manifest themselves at each level, and for different populations. Given the reciprocal interaction of organizations and their environments, we believe that research is needed on the various mechanisms considered in this article. Changes may come from within or from without. Thus, we offer examples and propose directions for research on them.
\end{abstract}

Keywords Social issues - Organiuzational process - Organizational context · Organizational environment

Tzafrir Shay, Enosh Guy, Parry Emma, and Stone Dianna contributed equally to this study.

\author{
T. Shay $(\bowtie) \cdot$ E. Guy \\ University of Haifa, Haifa, Israel \\ e-mail: stzafrir@research.haifa.ac.il \\ P. Emma \\ Cranfield School of Management, Cranfield, Bedford, UK
}

S. Dianna

University of Texas, San Antonio, TX, USA 
No organization is an island. The organization and its members are being affected and are affecting their internal and external contexts. The external and the internal contexts contain social environments which are of major significance for any organization. The organizational social environment includes any relationships between the organization and its members within the omnibus and discrete context. These relationships operate simultaneously at several levels (individual, team, organization, etc.), which may be analyzed from the perspective of discrete contexts (Johns 2006). Omnibus context refers to an entity that comprises many features or particulars whereas discrete context refers to particular variables or levers that shape behavior or attitudes (Johns 2006, p.391). Therefore, from an organizational point of view, this complexity requires the ability of the participants to comprehend the complexity of relationships, and the capability to create facilitating processes within the organization and between the organization and its external environment (Thompson and McEwen 1958). In order to do so, each actor should be able to decipher the development and codification of inter- and intra-relations between the external and internal environments. The purpose of this paper is to present a holistic perspective on the future outlook of the Journal of Managerial Psychology (JMP) regarding the role of social issues in organizational research.

The external environment interacts with the internal one through various mechanisms, including communication, observation, diffusion, interaction, friction, and yearning (CODIFY). Those mechanisms operate simultaneously yet differently at different systemic levels (community, organization, group, and individual). Actors (Including institutions, organizations, and people within them) need to develop awareness, strategies, and tactics for approaching those differing levels, the ways by which the various mechanisms manifest themselves at each level, and for different populations. For example, Lukaszewski and Stone (2012) mentioned the underutilization of the knowledge, skills, and abilities of disadvantaged populations such as women, ethnic minorities, older workers, and people with disabilities. At times of crisis, such populations tend to be the first that are being harmed. Utilizing the accumulated knowledge for differing omnibus and discrete contexts may facilitate the inclusion of such populations (Lukaszewski and Stone 2012). Studies of various omnibus and discrete contexts may fit the purpose of the Journal of Managerial Psychology. The following short descriptions relate the basic features of each of those contextual mechanisms.

Communication between the organization and the community and vice versa is carried on a daily basis. Communication between actors within and outside the organization may be perceived over several facets, described as continuums. While those continuums are presented herein in dichotomous terms, the reader may keep in mind that each par relates to the poles of a possible range. It may be direct or indirect; it may be open channeled or closed; the flow of information may be fast or slow; with different types and levels of noise. All of those facets of communication may have positive or negative impact on the behavior of organization's members, as well as of the organization itself. For example, Hoogervorst and colleagues (2004) have dealt with explicit and implicit communication in organizations and the way it shapes behavior. Another facet of communication concerns the technology used. At times of globalization, with phenomena such as virtual teams and teleworking 
becoming more and more common, the question of which technology should be used and when, becomes more and more important. For example, Graf, Koeszegi, and Pesendorfer (2010) have studied the issue of computer mediated technology in the context of intercultural interfirm relationships. In a similar vein, Caballer, Garcia, and Peiro (2005) focused on intellective tasks and found that "videoconference is the best fitted media and it should produce the highest affective response of group members" (p. 255) compared to face-to-face and email communication.

Observation refers to the way actors view, monitor, watch, and perceive other actors and themselves. It may be from inside the organization or from outside. Observation impacts the behavior of actors in the organizational field, and the community. It may lead to imitation (Bandura 1973), to criticism, affect ways of communication, and may impact the friction between actors. Following social learning theory (Bandura 1973), individual events may affect other levels of society and the organization through role-learning, imitation of behavior. For example, at the societal and organizational levels, the ecological "Green" movement has impacted the ways managers perceive and manage their organizations. At the individual level, Enosh, Tzafrir, and Gur (forthcoming) studying client violence toward service providers found that when clients are exposed to aggressive culture and behavior within the organization; they may imitate and learn through observation, that such behavior is acceptable and profitable. Therefore, they are encouraged to use aggressive behavior toward employees in order to achieve their goals. Through a process of social learning, various phenomena may lead to a gradual process of change in the planned behavior of stakeholders. Applying the theory of planned behavior, it is possible that while personal attitudes may or may not change, the subjective norms are reshaped, through learning that certain behaviors are acceptable and rewarding. Furthermore, stakeholders' perceived control (Ajzen and Madden 1986) may change, leading to the possibility of new behaviors that were previously unacceptable (Tzafrir and Enosh 2011).

Diffusion refers to the movement of norms, practices, and behaviors, across the boundaries of systems and subsystems. According to Rogers (2003) the diffusion process is the spread of an idea from its source to further actors and stakeholders (end users). The diffusion process depends on the openness of both sides. Metaphorically, one may think on the diffusion process as occurring through membranes. A membrane separates the organization from the environment, as well as between sub-systems within the organization. The permeability of such membranes defines the level of diffusion between the organization and its environment, and may be affected by the members of the organization, organizational practices, norms, regulations, etc. For example, Mazza and Alvarez (2000) have studied the diffusion of the idea of changing managerial practices from professional literature through popular press to the general society and business community. Abrahamson (1991) discusses the diffusion and rejection of managerial fads. Dodson and Muller (1978) have proposed a general model, including the interaction between adopters and non-adopters as well as the influence of external information sources such as advertising. Processes are diffused between different 
discrete contexts, from the personal level to the departmental and organizational levels, between organizations and between organizations and the wider society.

Interaction refers to frameworks of perception and activity between and among the various stakeholders, systems, and subsystems of which the organization and its environment consists of. As such it permits and is part of all omnibus and discrete contexts discussed in this paper. For example, the growing globalization in recent years has made the interaction between national value systems, Multinational Cooperation Cultures, and minority and immigrant workers an acute issue that needs to be managed (Hofstede 1985). As Thompson and McEwen (1958) have suggested:

"As a society becomes more complex and its productive activities more deliberately organized, social controls are increasingly exercised through such formal devices as contracts, legal codes, and governmental regulations. The stability of expectations provided by these devices is arrived at through interaction, and often through the exercise of power in interaction." (p. 25).

For example, Hosoda, Nguyen, and Stone-Romero (2012) found that in the discrete context of promotion for a high status job, applicants with a foreign accent faced more difficulty than applicants who lacked such accent; yet in the context of low status jobs, foreign accent may be an advantage. Accordingly, Stone-Romero and Stone (2007) have developed the model of stigmatization in organizations. The model differentiates between virtual social identity (VSI) and actual social identity (ASI). Researchers can apply the model to different populations such as persons with disabilities, women, minorities, and other disadvantaged groups.

Friction refers to conflicts, misunderstandings, and communication flaws between two or more actors. Cox (1991), putting the spotlight on multicultural organization, used the term friction for defining inter-group conflict. Yet, we claim that friction may occur at the individual, group, and societal levels. Friction may occur within the organization, outside of it, and between parts of the organization and the social environment. The phenomena of friction may have positive and/or negative impacts. It may enhance organizational change by motivating actors to achieve combined goals, or motivating competition toward organizational goals. For example, Napier and Thomas (2004) mentioned that in Vietnam friction exists especially when peers became managers. On the other hand, at certain times, reducing internal friction may facilitate overcoming resistance to change. Fisher and his colleagues (1997) differentiated between high and low friction environment and suggested that in some organizations, teams are "free from the friction between persons, and so, we would argue, they are a genuine team" (p. 239). Therefore, reducing internal friction may also help to overcome resistance to change in the intercultural encounter.

Yearning refers to the universal longing for the fulfillment of higher values such as equity, justice, cooperation, well being, and social responsibility. Through aspiring for the fulfillment of such values, stakeholders within and without the organization are building and maintaining respect, trust, and pride for themselves. For example, a case in point is the case of the Saturn corporation (Rubinstein 2000) in which unions and managers worked together in order to cope with the complex environment and achieved better organization performance. Barclay, Markel, and 
Yugo (2012), discussed virtue theory "as an approach to better recruit and integrate PWD [persons with disability] into the work environment" (pp. 340).

\section{Implications for Theory and Research}

Given the reciprocal interaction of organizations and their environments, we believe that research is needed on the various mechanisms considered in this article. For example, research is needed on the communication, observation, diffusion, interaction, friction, and yearning (CODIFY) at different systemic levels (e.g., community, organization, group, and individual). For example, we feel that much more research is needed on how the external environment or society influences communication, interaction, friction between internal and external environments and intra-organizational environments. Similarly, research is needed on how organizational actions affect society as a whole (Table 1).

For example, in 2008 there was a worldwide financial crisis spawned by a confluence of events including lax governmental regulations, unscrupulous or high risk lending practices, false advertising on the part of lenders, bankruptcies, and increased national debt levels. As a result of this crisis, many organizations downsized and workers across the world were laid off. Thus, the actions of organizations resulted in some friction with their external environments because high unemployment rates were very costly to societies. Similarly, these actions created a yearning for social justice, cooperation, and social responsibility on the part of organizations. Thus, we believe that additional research is needed on these issues including the friction and yearning for social justice and social responsibility. For instance, the unethical behavior of many corporate leaders had an impact on the financial crisis, and research is needed to understand the causes of this type of behavior as well as the strategies that can be used to deter it. In addition, research is needed to understand the psychological and physiological consequences of employee job loss (e.g., lowered self-esteem, depression, stress), and the strategies that displaced workers might use to gain new job opportunities (e.g., education, skills retraining). In 2012, the JMP published a special issue on job loss (Karren 2012), but we want to encourage authors to submit additional research on address unethical behavior in organizations, unethical leadership, and job loss to the journal.

Apart from the worldwide financial crisis, there are other changes in society that are affecting organizations. For instance, there are demographic changes occurring around the world. The population of many countries are aging (e.g., Japan, U. S., European Union), and this has caused a shortage of talented employees. As a result, there is an increase in immigration to those countries that do not have enough workers to fill key jobs. The rise in immigration has created some friction, and spawned concern about the social exclusion of migrants and minority group members. The increased numbers of migrants and minority groups members has also creating yearning for just societies that do not tolerate unfair discrimination, workplace bullying, and unfair treatment in the workplace (Lukaszewski and Stone 2012). Thus, we believe that additional research is needed to understand the causes of unfair discrimination against immigrants, ethnic minorities, women, racial 


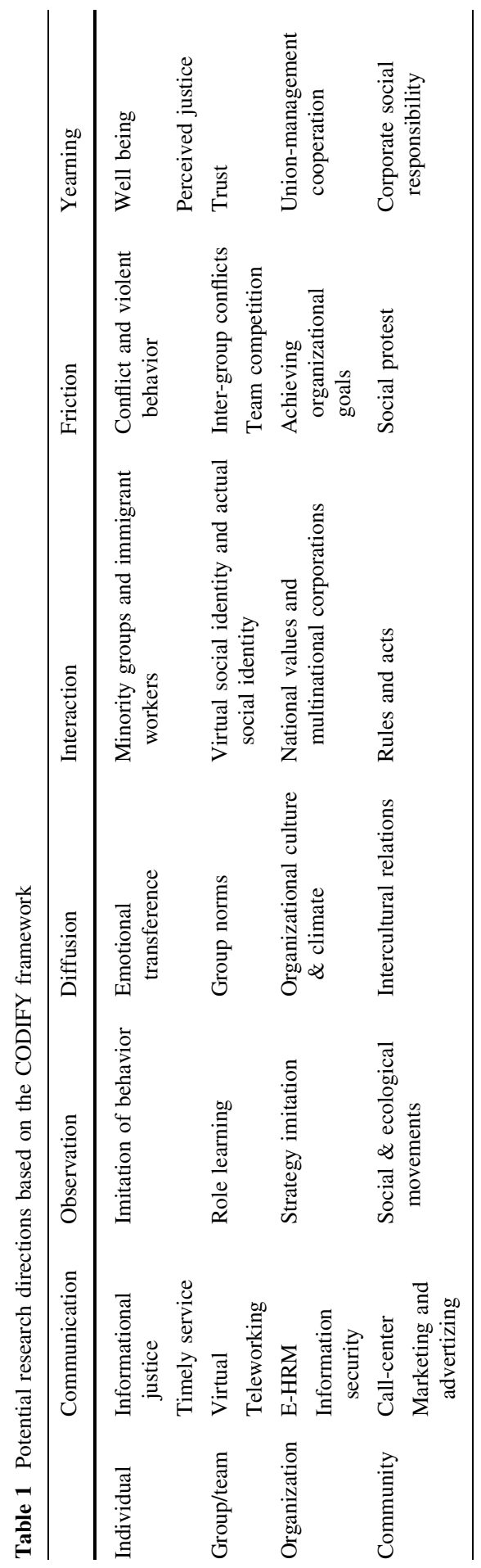


minorities, and other out-group members who are not given equal opportunities to gain access to jobs or a satisfying work life. The JMP has published special issues on the aging workforce (Peeters and van Emmerik 2008), unfair discrimination against immigrants (Dietz 2010), and other forms of unfair treatment (Lukaszewski and Stone 2012). However, we would like to encourage authors to submit additional theory and research on these issues to the journal.

In addition, we believe that organizations should develop human resource strategies that can be used to deal with the aging workforce and the resultant shortage of talent. These strategies might include alternative work arrangements such as part-time work, flextime, telework so that older workers can stay on the job. Furthermore, organizations might want to find ways of encouraging young workers to gain skills in careers that are currently underrepresented in the workplace. For example, in the U. S. there are shortages of talented employees in computer science, software engineering, machinists and welding positions, and nursing and other jobs in healthcare. In addition, organizations may want to start knowledge sharing and mentoring programs that enable older workers to pass their knowledge along to those who will replace them. Although these strategies seem plausible, additional research is needed to assess their effectiveness before they are implemented in organizations. Thus, the JMP welcomes theory and research on strategies for reducing unfair discrimination, alternative work arrangements that would enable older workers to remain on jobs, and career strategies that would help young workers seek training in underrepresented careers.

Even though there are many changes in society that are affecting organizations, one important change is the rise in technology. Technology affects internal organizational operations in many ways, and affects the communication processes within and between organizations and their environments. One of the most dramatic changes from a human resources point of view is that most jobs are performed online or via the Internet. As a result, there is less face-to-face communication between individuals, and it has been replaced with encounters with unknown individuals and other computer systems (Gutek 1995). Furthermore, many of the human resource practices that were performed by human resource professionals have now been replaced with online systems. For instance, about 80 percent of large organizations conduct recruitment online, and a large number of companies use electronic selection systems which include Internet-based tests or electronic interviews (Gueutal and Stone 2005). Likewise, employees now use self-service human resource information systems to manage their benefits and select options for their health care and retirement.

Although most of the research on the impact of technology on HR management has focused on its effectiveness, research is needed to examine its impact on the well being of individuals. For example, will individuals become alienated and psychologically distant from others if they conduct most of their transactions with organizations online? Similarly, will employees receive the same quality of benefits or job opportunities if they choose them without the aid of a human resource professional? Likewise, will these new systems have a negative impact on communication or friction between individuals and organizations, or increase the yearning for social justice and fair treatment for all those involved? 
There are several concerns about the use of online systems in organizations one of which is privacy. For instance, there are growing concerns that the release and storage of personal information in an HRIS will increase the extent to which sensitive information is released to others which may result in negative outcomes for individuals (e.g., embarrassment, loss of job opportunities, etc.). Another concern is that the increased use of technology including computers, cell phones, Internet, email, voice mail, social networking websites, etc. will result in role overload and higher stress levels among employees who are teathered to technology $24 \mathrm{~h}$ per day. Even though there has been some research on the acceptance of electronic human resource systems (eHRM) (e.g., Gueutal and Stone 2005), much more research is needed on the effects of technology on communication, friction, and yearning processes. In 2009, the JMP published a special issue on eHRM (Gueutal 2009), but much more theory and research is needed to understand the impact of technology on individuals, organizations, and the interface between organizations and their environments.

\section{Conclusion}

In summary, it is clear that no organization operates as an island, but experiences a complex interaction with its external environment including society as a whole. Furthermore, there is a reciprocal relationship between organizations and society, and some researchers argue that it is a symbiotic relationship (Katz and Kahn 1966). Thus, this article outlined several mechanisms that influence the interaction between external and internal organizational environments including CODIFY. We also offered examples of changes in the external environment or society that may affect the internal organizational environment, and offer directions for research on them. It is our hope that this article sparks an interest in the reciprocal relationship between external and internal organizational environments, and fosters research on a number of social issues that stem from this relationship.

\section{References}

Abrahamson, E. (1991). Managerial fads and fashions: The diffusion and rejection of innovation. Academy of Management Review, 16, 586-612.

Ajzen, I., \& Madden, T. J. (1986). Prediction of goal-directed behavior: Attitudes, intentions, and perceived behavioral control. Journal of Experimental Social Psychology, 22, 453-474.

Bandura, A. (1973). Aggression: A Social Learning Analysis. Englewood Cliffs: Prentice-Hall.

Barclay, L. A., Markel, K. S., \& Yugo, J. E. (2012). Virtue theory and organizations: Considering persons with disabilities. Journal of Managerial Psychology, 27, 330-346.

Caballer, A., Gracia, F., \& Peiró, J.-M. (2005). Affective responses to work process and outcomes in virtual teams: Effects of communication media and time pressure. Journal of Managerial Psychology, 20, 245-260.

Cox, T. Jr. (1991). The multicultural organization. Academy of Management Executive, 5(2), 34-47.

Dietz, J. (2010). Introduction to the special issue on employment discrimination against immigrants. Journal of Managerial Psychology, 25, 104-112. 
Dodson, J. A., \& Muller, E. (1978). Models of new product diffusion through advertising and wordof-mouth. Management Science, 24, 1568-1578.

Enosh, G., Tzafrir, S., \& Gur, A. Client aggression towards social workers and social services in IsraelA qualitative analysis. Journal of Interpersonal Violence, (Forthcoming).

Fisher, S. G., Hunter, T. A., \& Macrosson, W. D. K. (1997). Team or group? Managers' perceptions of the differences. Journal of Managerial Psychology, 12(4), 232-242.

Graf, A., Koeszegi, S. T., \& Pesendorfer, E. M. (2010). Electronic negotiations in intercultural interfirm relationships. Journal of Managerial Psychology, 25(5), 495-512.

Gueutal, H. G. (2009). HR and our virtual business world. Journal of Managerial Psychology,24.

Gueutal, H. G., \& Stone, D. L. (2005). The brave new world of eHR: Human resources management in the digital age. San Francisco: Jossey-Bass.

Gutek, B. (1995). The dynamics of service. Reflections on the changing nature of customer/provider interface. San Francisco: Jossey-Bass.

Hofstede, G. (1985). The interaction between national and organizational value systems. Journal of Management Studies, 22.

Hoogervorst, J., van der Flier, H., \& Koopman, P. (2004). Implicit communication in organizations: The impact of culture, structure and management practices on employee behavior. Journal of Managerial Psychology, 19, 288-311.

Hosoda, M., Nguyen, L. T., \& Stone-Romero, E. F. (2012). The effect of Hispanic accents on employment decisions. Journal of Managerial Psychology, 27, 347-364.

Johns, G. (2006). The essential impact of context on organizational behavior. Academy of Management Review, 31, 386-408.

Karren, R. (2012). Introduction to the special issue on job loss. Journal of Managerial Psychology, 27, $772-779$.

Katz, D., \& Kahn, R. L. (1966). The social psychology of organizations. New York: Wiley.

Lukaszewski, K. M., \& Stone, D. L. (2012). Theory and research on social issues in organizations. Journal of Managerial Psychology, 27, 324-329.

Mazza, C., \& Alvarez, J. L. (2000). Haute Couture and Prêt-à-Porter: The popular press and the diffusion of management practices. Organization Studies, 21, 567-588.

Napier, N. K., \& Thomas, D. C. (2004). Managing relationships in transition economies. Westport: Praeger.

Peeters, M. C. W., \& van Emmerik, H. (2008). An introduction to the work and well-being of older workers: From managing threats to creating opportunities. Journal of Managerial Psychology, 23, $353-363$.

Rogers, E. M. (2003). Diffusion of innovations (5th ed.). New York: Free Press.

Rubinstein, S. A. (2000). The impact of co-management on quality performance: The case of the Saturn corporation. Industrial and Labor Relations Review, 53(2), 197-218.

Stone-Romero, E. F., \& Stone, D. L. (2007). Cognitive, affective, and cultural influences on stigmatization: Impact on human resource management processes and practices. Research in Personnel and Human Resources Management, 26, 117-167.

Thompson, J. D., \& McEwen, W. J. (1958). Organizational goals and environment: Goal-setting as an interaction process. American Sociological Review, 23, 23-31.

Tzafrir, S. S., \& Enosh, G. (2011). Beyond attitudes and norms: Trust commitment and HR values as triggers of intention to leave. In R. Searle \& D. Skinner (Eds.), Trust and human resource management (pp. 289-308). Cheltenham: Edward Elgar Pub. 